\title{
THE FIRST CAVERNICOLOUS NICOLETIIDAE (INSECTA: ZYGENTOMA) FROM THE UNITED ARAB EMIRATES
}

\author{
Luis Espinasa ${ }^{1}$ And Luis F. Mendes²
}

\begin{abstract}
Lepidospora mazyadi, n. sp., is described and differentiated from all the other known Lepidospora s.s. The new species was collected from a cave in Jebel Hafeet in the United Arab Emirates. Morphology and preliminary analyses of 16S rRNA DNA sequences are described. The new species is unique because, unlike other species in the genus, it lacks sexually dimorphic terminal filaments. It is also the first nicoletiid reported from the United Arab Emirates and the second cave-adapted species from Arabia.
\end{abstract}

\section{INTRODUCTION}

In 1997, a cave was encountered during construction work on the top of Jebel Hafeet, near the village of Mazyad in the United Arab Emirates. Subsequent exploration of the cave showed it to have 450 meters of passage and a depth of 96 meters, becoming the longest cave in the UAE. During the original explorations, nicoletiid insects were observed and collected, but samples where too degraded to be identified. In 2011, another exploration trip was conducted during which six specimens were successfully collected. A description of this new species of nicoletiid and preliminary DNA sequence data are provided here.

\section{Materials AND Methods}

Dissections were made with the aid of a stereo microscope. Illustrations were made with the aid of a camera lucida attached to a microscope. Specimens will be deposited in the collection of the American Museum of Natural History, New York.

Genomic DNA from the holotype and a female paratype were extracted using Qiagen's DNEasy Tissue Kit by digesting a leg in lysis buffer. Amplification and sequencing of the 16S rRNA fragment was done as in Espinasa and Giribet (2009) following standard protocols with primers used in the past for nicoletiids. Chromatograms obtained from the automated sequencer were read and contigs made using the sequence editing software Sequencher 3.0. External primers were excluded from the analyses. Sequences were aligned and neighbor-joining analysis was performed with ClustalW2.

\section{Results AND Discussion}

Molecular data were obtained from two individuals. A partial 16S rRNA fragment 486 bp in length was obtained (Fig. 1). Both specimens had identical sequences. Nucleotide alignment of the UAE specimen with other species of Nicoletiids from which 16S rRNA sequence are available showed considerable sequence differences. A neighborjoining tree showed the new species distantly related to
Australiatelura, an inquiline species of the subfamily Atelurinae from Australia and New Zealand (111 bp differences; $22.8 \%$ ). Nevertheless, these results should be considered as preliminary. With the exception of the American nicoletiids of the subfamily Cubacubaninae, very few studies on the Old World nicoletiids have used DNA sequencing, and it is likely that other unsequenced species are more closely related.

\section{LEPIDOSPORA MAZYADI, EsPINASA AND MENDES}

NEW SPECIES

(Figs. 2A-H, 3A-G)

Material: Holotype male, body $10 \mathrm{~mm}$, tarsus third leg $1.1 \mathrm{~mm}$. Paratypes: one male $(9 \mathrm{~mm})$, three females $(13,13$, and $12 \mathrm{~mm}$ ), and one juvenile $(5.5 \mathrm{~mm})$. In the vicinity of 40R 375360 E / 3661550 N, Magharet Qasir Hafeet Cave, Jebel Hafeet, near the village of Mazyad and the city of Al Ain, Emirate of Abu Dhabi, United Arab Emirates. 6/17/ 2011 and 8/8/2011. Collected by Tim Fogg, Pam Fogg, Angus Tillotson, and Abdul Raheem Abdul Rahman Iqtedar Al Marzooqi.

DESCRIPTION: Body proportions as in Figure 2A. Maximum body length of male $10 \mathrm{~mm}$, of female $13 \mathrm{~mm}$. Maximum conserved length of antennae and caudal appendages $8 \mathrm{~mm}$. Head and body with typical scales (Figs. 2B, 2G, 3B-C, and 3F). General color light yellow to white. Head with scales, macrochaetae, and microchaetae as shown in Figure 2B. Pedicellus of male slightly shorter than first article and with a distinct protuberant apophysis that extends inwards and ventrally (Fig. 2B-C). On the apophysis basally there are multiple microchaetae and distally a couple of macrochaetae and a distinct small spiniform chaeta on its apex (Fig. 2C). Basal articles of antennae of female simple.

Appendages long, as in other cave-adapted nicoletiid species. This is most evident in the maxillary palp, which is particularly long (Figs. 2A and 2E). Mandible chaetotaxy as in Figure 2H, with about five macrochaetae on central-distal

\footnotetext{
${ }^{1}$ School of Science, Marist College, 3399 North Road, Poughkeepsie, NY 12601. luis.espinasa@marist.edu

${ }^{2}$ Instituto de Investigação Científica Tropical - JBT / CZ. R. da Junqueira, 14 1300343 Lisboa, Portugal. luis.mendes@iict.pt
} 
GTCAGGCCTGCTCGATGATTGTTTAAATGGCCGCGGTATTTTGACCGTGCAAAGGTAGCATAATCATTAGTCTTTTA AATGGGGGCTTGTATGAATGGTTAGACGAAAGGGGGTCTTTCTTATAAGAATAGTTTGTATGAATTTTACCTTTTTG TGAAAAGGCTGAAATAATTTAARGGGACGATAAGACCCTATAGATCTTTATGGTTGATTGATCTTATAATCTACTAG GATTTGTATAATATTTATCAATTGTTTAGCTGGGGCGGTTGGGAGATATATTTAACTCTCTTTAGGGTATTTATTTA TTTATATTTTTTGATCCTTATTTAGTGGATAGAAGACTAAGTTACCTTAGGGATAACAGCGTAATCTTTTTGGAGAG TTCTTATCGATAGAAGGGTTTGCGACCTCGATGTTGGATTAAGGTTACTTTCTGGTGAAGGAGCTGGAGAAGTTAGT CTGTTCGACTATTAAAACCTTACA

\section{Figure 1. 16S rRNA fragment sequence of Lepidospora mazyadi n. sp.}

portion. Maxilla as shown in Figure 2E. Last article of subequal length to penultimate article. Apex of galea with two subequal conules and two teeth on lacinia (Fig. 2F). Labial palp as in Figure 2D, with apical article distinctly longer than wide and longer than the penultimate article.

Pro-, meso-, and metanota with several macrochaetae on postero-lateral margins, apart from several setae of varied sizes (Fig. 2G). Legs long; hind tibia about $8 \times$ longer than wide and one fifth shorter than tarsus (Fig. 3A).

Abdominal tergites as in Figure $3 \mathrm{~F}$, with robust macrochaetae on their posterior edges. Urotergite $\mathrm{X}$ protruding, very deeply emarginated in both sexes, but more so in males. In males multiple macrochaetae plus two rows of scleritized pegs, one lateral (Fig. 3F) and the other ventral (Fig. 3G). The tips of urotergite $\mathrm{X}$ also with scleritized pegs (Fig. 3F). Depth of emargination almost as deep as the macrochaetae and slightly wider (Fig. 3F-G). In females urotergite $\mathrm{X}$ slightly less deep, without lateral and ventral pegs, but instead of the pair of pegs at the tips they have a distinct large macrochaetae.

Abdominal sternites as in Figures 3B-D. Urosternite I divided into a median sternite and $1+1$ lateral coxites. Urosternites I-VIII entire. Stylets in urosternites II-IX. Stylets have a terminal spine with small teeth and ventrally with two macrochaetae plus another distal pair (Fig. 3BD). Stylets IX larger than others (Fig. 3C-D). Posterior margin of urosternite VIII of male prominent, straight, and with a couple of macrochaetae (Fig. 3C). Penis and paramera as in Figure 3C. Paramera long, almost $8 \times$ longer than wide. Paramera attain about two thirds the length of stylets IX in the largest male $(10 \mathrm{~mm})$. Subgenital plate of female triangular to sub-parabolic (Fig. 3D). In the largest female $(13 \mathrm{~mm})$, the ovipositor surpasses apex of stylets IX by two thirds the length of stylets (Fig. 3D). Gonapophyses with about 14 to 15 annuli. Male and female cerci and appendix dorsalis simple. Cerci with trichobothria. (Fig. 3E).

Postembryonic Development: Only partially understood due to sample size. Both males 10 and $9 \mathrm{~mm}$ share equal characteristics: pedicellus with distinct protuberant apophysis and parameres attain about two thirds the length of stylets IX. In the three females $(13,13$, and $12 \mathrm{~mm}$ ) the ovipositor surpasses apex of stylets IX by two thirds to one half the length of stylets and gonapophyses with about 14 to 15 annuli. The species appears to share with other cavernicolous species a rather late sexual development. The single juvenile is quite large, and at
$5.5 \mathrm{~mm}$ long it has yet to develop either male or female character, and paramera or ovipositor are absent.

Eтymology: mazyadi. From the nearby village of Mazyad, where the cave is located.

Remarks: The new species belongs within the subfamily Coletiniinae because it has urosternite I divided, II-VIII entire, and coxites IX of male free, male pedicellus with an apophysis without apparent glands, and parameres not divided (Mendes, 1988). It belongs within the genus Lepidospora because stylets are present on urosternites II-IX and they have typical scales (Wygodzinsky, 1980). It belongs to the nominate subgenus because there are scales on both the body and on the cephalic capsule. It can be differentiated from other species within the genus by the complete lack of sclerotized pegs on all three terminal filaments in the male (cerci and paracercus). It is immediately distinguishable from the only other Lepidospora known from the Arabian Peninsula, L. (L.) angustotergum, a troglobiont or deep edaphic species from southeastern Oman (Mendes, 2002a), by the quite different urotergite $\mathrm{X}$, shorter and less delicate paramera, and lack of submedian macrochaetae on urosternite VIII in the male. Females are differentiated by the distinct subgenital plate and much longer ovipositor.

The new species enters the identification keys previously proposed for the genus (Mendes, 2002b) at point 3 for the males, as all remaining known Lepidospora have pegs at least on the cerci, as reported earlier. The female runs to couplet 21, and is quite different from $L$. (L.) angustotergum, as mentioned before. It is not possible to enter the other option $\left(21^{\prime}\right)$ due to the adult size and the elongation of the appendages. The two most recently described species, both epigean from the Socotra Islands (Mendes, 2004), were described after the key was proposed. They can be differentiated from the new species because males have sclerotized pegs on the cerci and paracercus, by the elongation of legs, maxillary and labial palps, by the size and slenderness of paramera, and by the shape of both the antennal pedicellus and of urotergite $\mathrm{X}$. Females are unknown in these species.

Distribution: Known only from type locality.

\section{ACKNOWLEDGMENTS}

The President of the United Arab Emirates, His Highness Sheikh Khalifa bin Zayed Al Nahyan, is thanked for his support for the research into the Magharet Jebel 

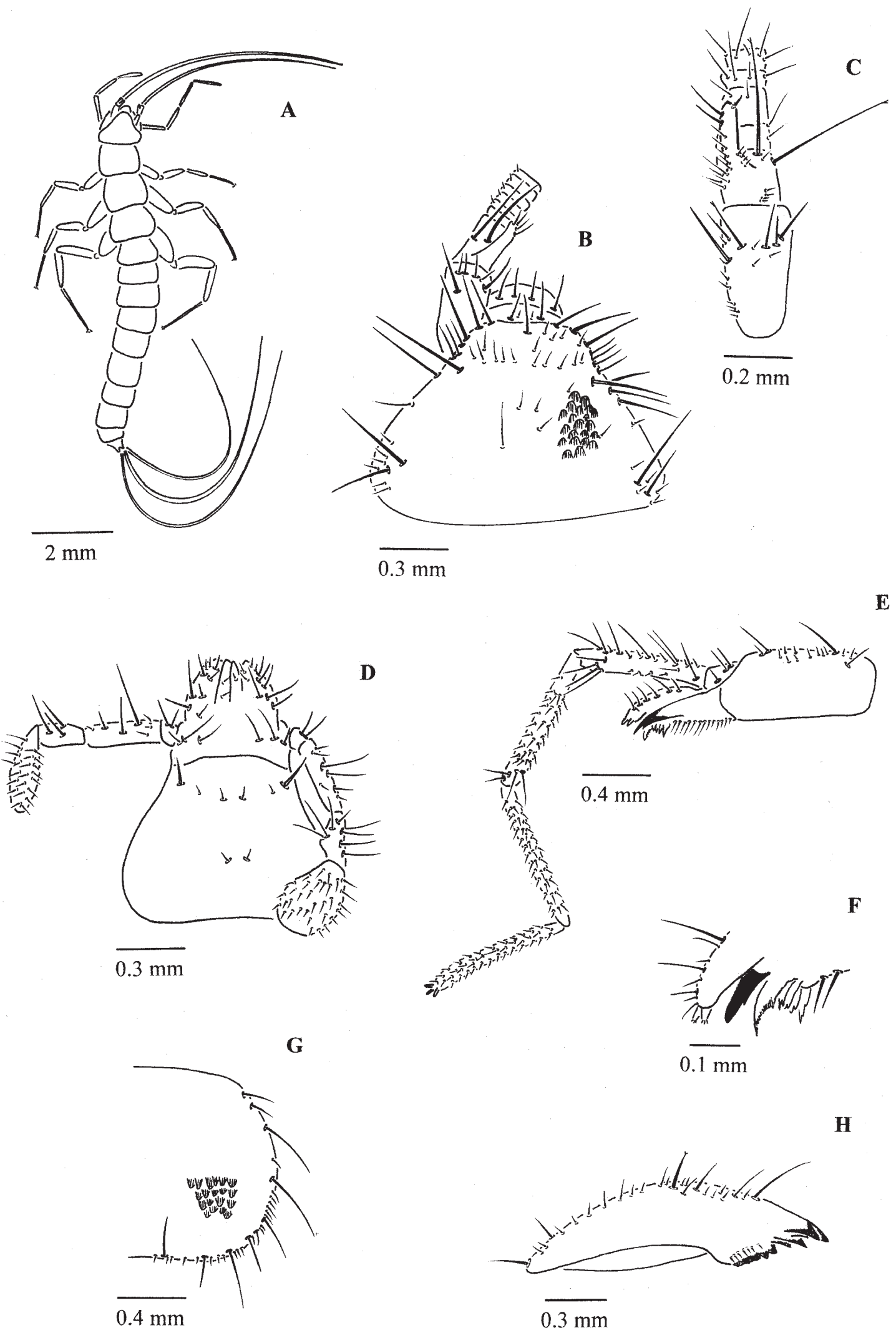

$\mathbf{E}$
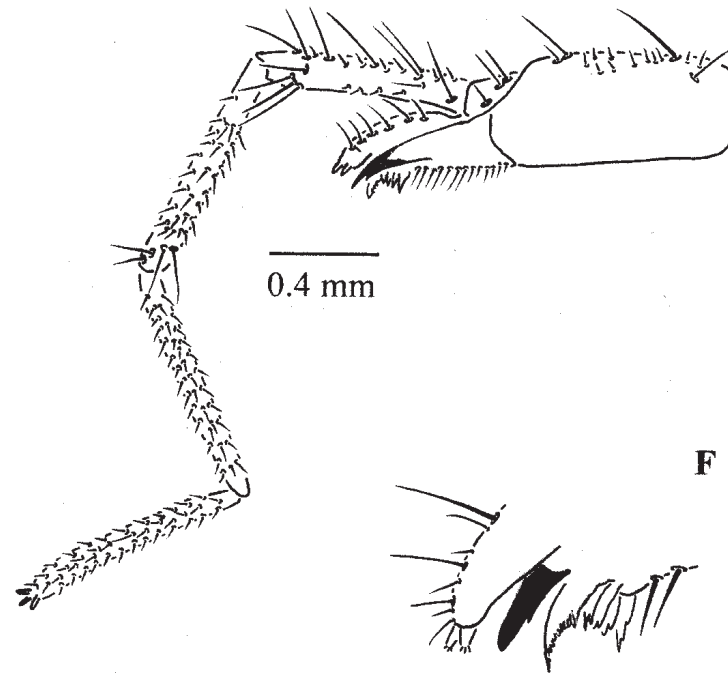

$0.1 \mathrm{~mm}$

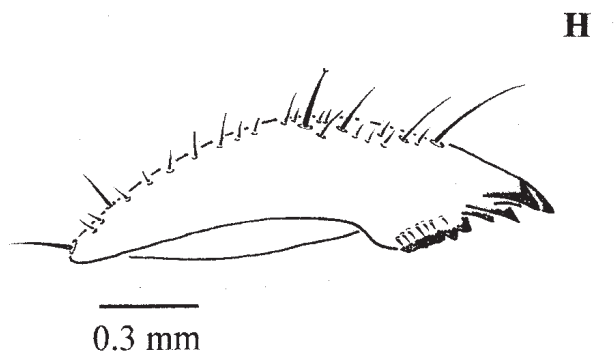

Figure 2. Lepidospora mazyadi n. sp. Scales and microchaetae partially shown. A, Body. B, Head and antennae. C, Ventral view of basal portion of antennae. D, Labium. E, Maxilla. F, Apex of maxilla. G, Thoracic nota. H, Mandible. 

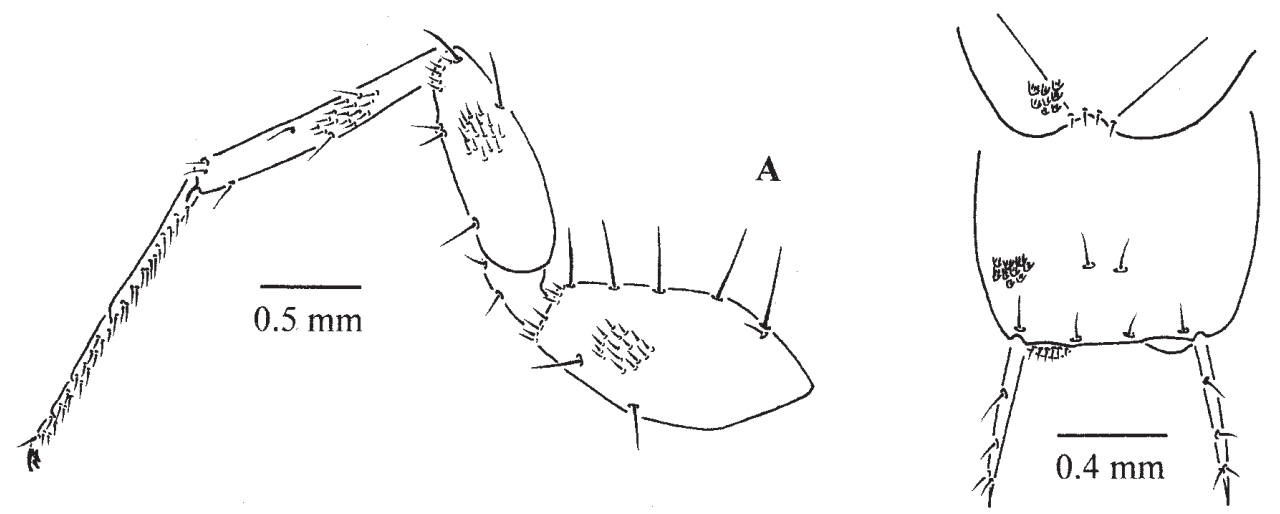

B

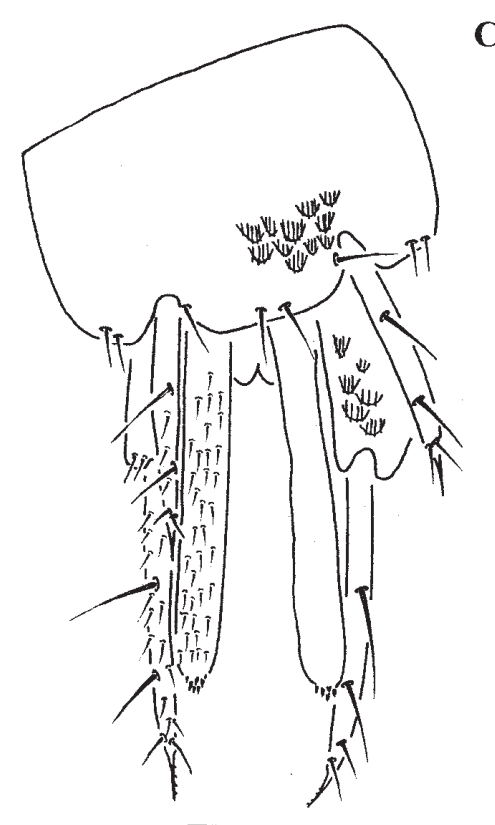

C
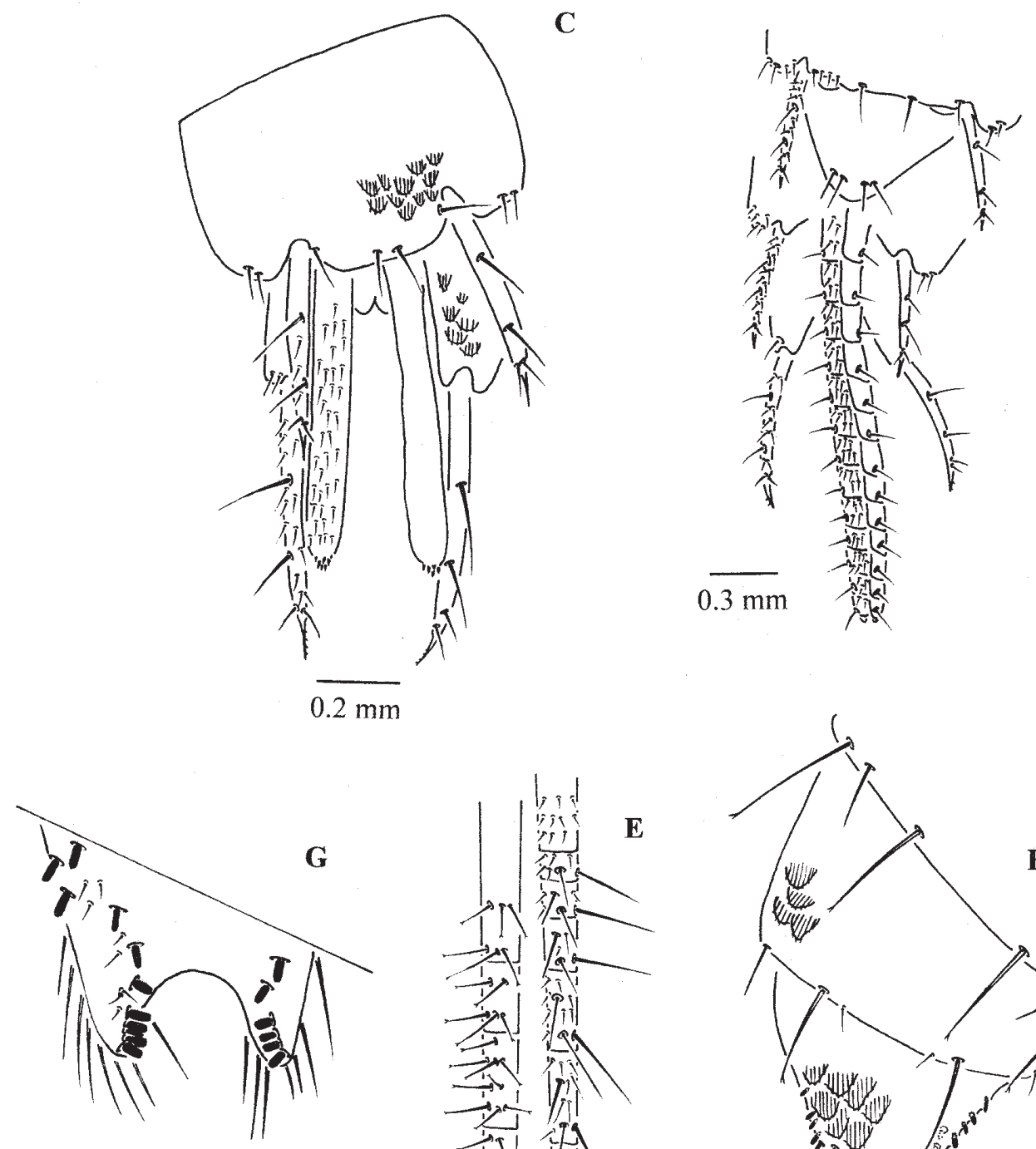

$0.1 \mathrm{~mm}$

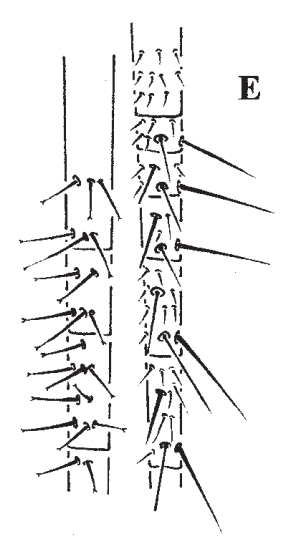

$\overline{0.3 \mathrm{~mm}}$

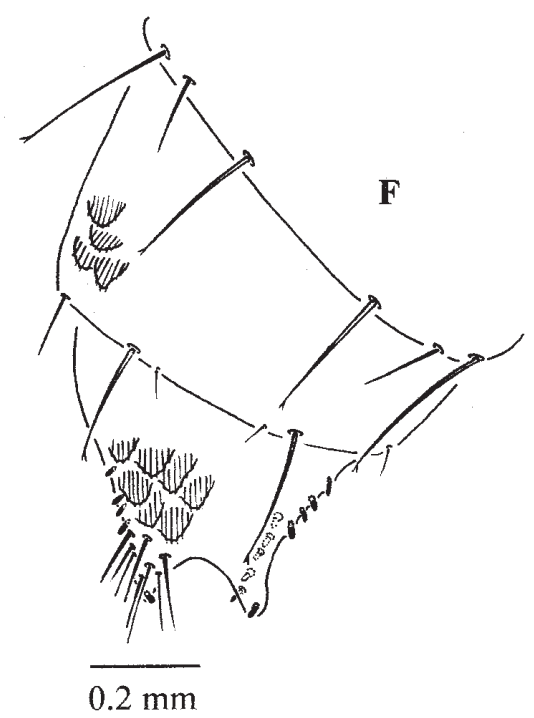

Figure 3. Lepidospora mazyadi n. sp. Scales and microchaetae partially shown. A, Hind leg. B, Urosterna I and II. C, Genital area of male. D, Genital area of female. E, Caudal appendages. F, Dorsal view of uroterga VIII-X (ventral pegs represented with dots on one single side). G, Ventral view of urotegite $\mathrm{X}$. 
Hafeet cave from which the specimen was identified. H.E. Mubarak Sa'ad al-Ahbabi, Chairman of the Department of The President's Affairs, Nick Cochrane-Dyet, and Peter Hellyer for facilitating the study of the nicoletiid specimens. Pam and Tim Fogg were both collectors and our liaison for sources of information. DNA was sequenced by students of the genetics course (BIOL320) at Marist College. We thank Graeme Smith and Julian J. Lewis for reviewing the manuscript.

\section{REFERENCES}

Espinasa, L., and Giribet, G., 2009, Living in the dark-species delimitation based on combined molecular and morphological evidence in the nicoletiid genus Texoreddellia Wygodzinsky, 1973
(Hexapoda: Zygentoma: Nicoletiidae) in Texas and Mexico, in Colkendolpher, J.C., and Reddell, J.R., eds., Studies on the Cave and Endogean Fauna of North America V, Austin, Texas Memorial Museum Speleological Monographs 7, p. 87-110.

Mendes, L.F., 1988, Sur deux nouvelles Nicoletiidae (Zygentoma) cavernicoles de Grèce et de Turquie et remarques sur la systématique de la famille: Revue Suisse de Zoologie, v. 95, p. 751-772.

Mendes, L.F., 2002a, On a new Lepidospora s.s. (Zygentoma: Nicoletiidae) from Oman: Revista Brasileira de Zoologia, v. 24, no. 1/2, p. $107-112$.

Mendes, L.F., 2002b, Some new data and descriptions of thysanurans (Zygentoma: Nicoletiidae) from Central and Eastern Africa: Annales du Musée royal de l'Afrique Centrale, Zoologie, v. 290, p. 87-127.

Mendes, L.F., 2004, Zygentoma (Insecta) from the Socotra Archipelago: Fauna of Arabia, v. 20, p. 357-398.

Wygodzinsky, P.W., 1980, A survey of the Nicoletiinae of Europe (Nicoletiidae, Thysanura, Insecta), American Museum Novitates no. 2695,24 p. 